\title{
"REPRESENTAÇÕES" DE GÊNERO EM IMAGENS: CONTRIBUIÇÕES METODOLÓGICAS \\ DE UMA SOCIOLOGIA DO CINEMA
}

\section{GENDER "REPRESENTATIONS" IN IMAGES: METHODOLOGICAL CONTRIBUTIONS FROM A CINEMA SOCIOLOGY}

Túlio Cunha Rossi*

\section{Introdução}

Este texto condensa reflexões resultantes de profunda revisão bibliográfica sobre gêneros e suas relações possíveis com estudos sociológicos de imagens e mídias audiovisuais, com destaque para o cine$\mathrm{ma}^{1}$. Ao aprimorar o contato com trabalhos existentes na área sob perspectivas feministas e queer, identificou-se a recorrência do termo "representações", notando-se que, além das discussões e análises de imagens, as questões em torno de representações destacando-se aqui aquelas que se propõem como do feminino -, assumem grande im- portância política e no campo de produção e reconhecimento de identidades. Nisso, a representação emerge não somente como tema de debates em diferentes vertentes de estudos de gênero, mas assume papel central nas tentativas de definição de categorias políticas, sendo frequentemente utilizada numa ampla e difusa variedade de sentidos e contextos, às vezes sem mediação clara. Por vezes, a palavra parece utilizada como vocabulário do senso comum, aludindo a uma relação maniqueísta entre "verdadeiro" e "falso", no que muitos parecem se preocupar em apontar crítica e exaustivamente a falsidade da representa-

\footnotetext{
* Doutor em Sociologia pela Universidade de São Paulo - USP. Professor Adjunto do Departamento de Ciências Sociais da Universidade Federal Fluminense (Campos/RJ/BR). tuliorossi@gmail.com.

1. Destaca-se, de saída, que este artigo propõe tanto diálogos com estudos feministas e queer, quanto críticas que se pretendem construtivas, mas marcando, desde o início, que o texto é construído prioritariamente sob perspectivas sociológicas de estudos do cinema e mídias audiovisuais.
} 
ção tendenciosamente aglutinadora frente à "realidade por excelência" ${ }^{2}$, consideravelmente difusa.

Quando a questão das representações de gêneros é transposta para análises sociológicas de imagens e filmes, problemas maiores emergem, uma vez que o debate sobre representações e as relações entre imagem e realidade, nesse tipo de estudo específico, assume ainda outras nuances e polêmicas. Aqui, a comparação simplista entre o "real" e sua representação já se revelou inócua, especialmente a partir de estudos aprofundados sobre produções cinematográf1cas que suscitam aspectos peculiares dessa mídia enquanto linguagem e construção. Desse modo, a despeito das impressões persuasivas de realidade que ela possa instigar, seus referenciais mais caros não estariam no princípio da fidedignidade, mas nos significados nelas mobilizados (cf. SORLIN, 1982; MENEZES, 2003, ROSSI, 2015).

A partir desses entendimentos e das dificuldades que emergiram na leitura de diferentes textos abordando ou não a questão das imagens, associada à temática de gêneros, mas mobilizando - às vezes, de forma exaustiva - o termo "representação”, este artigo propõe, nomeadamente no campo das imagens, instigar questões mais específicas que contribuam para superar a abordagem pautada por noções difusas de representação em relação quase sempre maniqueísta com noções de realidade. Nesse sentido, primeiramente, problemati- za-se o termo em estudos de gênero, para, em seguida, mais pontualmente, tratar de seus usos em estudos de imagens, sugerindo uma abordagem alternativa pautada por relações entre imagens para, ao final, tecer considerações sobre desdobramentos de relações profundamente constituídas em sociedades modernas entre construções sociais do gênero feminino apresentadas como "hegemônicas" e suas imagens, sustentando o relevante potencial de contribuição de estudos de imagens e produções audiovisuais para a compreensão de (re) construções sociais de crenças e valores referentes a gêneros na atualidade.

\section{A polissemia do termo representação}

São recorrentes, em estudos de gênero, debates em torno das representações, termo muitas vezes utilizado de forma mais específica em estudos de imagens e em produções artísticas e midiáticas como pintura, fotografia, cinema e programas televisivos e anúncios publicitários (ALMEIDA, 2003; HIGONNET, 1991; PASSERINI, 1991; LAURETIS, 1994, et. al.). Não raramente, o termo parece assumir significados e leituras quase tão diversas quanto o número de autores que o empregam. Em muitas ocasiões, leitores e debatedores de posicionamentos diversos em relação ao tema parecem usar a expressão de forma naturalizada, sem problematizar as suas implicações ou explicitar a partir de qual perspectiva ela é utilizada.

2. Essa expressão refere-se à perspectiva de "realidade da vida cotidiana" entendida conforme Berger e Luckmann (1983, p. 38), sendo que se concorda com a proposta desses autores de que a noção de realidade deve ser sempre colocada em questão e pensada "entre aspas". Tendo essa leitura em vista, o termo realidade (e seus cognatos) será utilizado ao longo do texto sempre sob tal perspectiva, qual seja: pensar a noção de realidade entre aspas, não como dado geral, objetivo e absoluto, mas como um conjunto difuso de interpretações e convenções (re)construídas de forma interacional e persistente. 
Em seu trabalho Um panorama dos estudos sobre midia, sexualidades e gêneros não normativos no Brasil, embora Leandro Colling (et. al., 2012) realize importante levantamento sobre a presença de imagens de "gêneros não normativos" no cinema brasileiro e os modos como essa presença se dá, o termo representação é utilizado dispensando conceituação, para se referir às imagens construídas no cinema, aquilo que os próprios autores chamam de gêneros não normativos, ressaltando o modo pejorativo e estereotipado com que essas imagens são construídas. Não se questiona aqui tal conclusão, devidamente fundamentada pelos autores. A questão é o artigo não problematizar o termo "representação" nos estudos de mídia e usá-lo apenas de maneira adjetivada para realçar o aspecto pejorativo com que personagens homossexuais tendem a ser construídos no cinema comercial brasileiro, sugerindo implicitamente, como entre outros estudos uma relação maniqueísta entre uma representação "verdadeira" (quando auto-representação ${ }^{3}$ ) e uma representação "falsa" e, necessariamente, pejorativa. Nesse sentido, além do uso do termo "representação" não ser devidamente tratado nem como conceito e nem como categoria analítica, quando confrontado com outros estudos, ele se mostra insuficiente do ponto de vista sociológico sobre imagens e seus potenciais efeitos na vida social. A constatação e o reconhecimento de que "sexualidade e gêneros não normativos" (COLLING et al., 2012) têm pouca visibilidade nas mídias e nos meios de comunicação de massa é reconhecidamente importante, mas também primária. Cabe aos estudos de imagens - quando de perspectivas sociológicas - superarem o mero aspecto de ilustração e reiteração de alguma constatação prévia. E isso é válido tanto para os estudos de gêneros, quanto de outros temas caros às ciências humanas como o trabalho, a religião, a política e qualquer outro que se proponha utilizar do cinema e das mídias audiovisuais apenas para ilustrar suas observações sem, contudo, problematizar os modos como essas imagens são produzidas, quais relações de valores estabelecem e quais discursos e crenças evocam, inclusive - e, talvez, principalmente - no que não mostram. De modo que, da mesma forma que nos parece ingênuo utilizar o cinema para "ilustrar" a realidade, parece-nos inócuo e dispensável utilizá-lo para afırmar que este não corresponde a uma "representação" fiel da mesma.

Desse modo, sob uma perspectiva sociológica, pouco é acrescentado sobre a maneira como essas produções midiáticas participam e interferem na constituição e reiteração de relações desiguais e heteronormativas de gênero, limitando-se a constatar a existência já observada em tantos outros estudos sob incontáveis perspectivas analíticas. Em suma, cai-se facilmente em uma tautologia que pouco explora os potenciais oferecidos por estudos sociológicos de imagens e mídias audiovisuais para compreender - e, efetivamente, transformar - as realidades sociais onde essas desigualdades são [re]produzidas e reiteradas.

0 termo representação, de caráter polissêmico, transita em diferentes áreas de conhecimento e debate, assumindo signi-

2. Reitera-se aqui que a crítica apresentada não se propõe generalizante. São encontrados trabalhos em que os conceitos e referências utilizados para o termo "representação" são adequadamente apresentados, bem como uma análise crítica e reflexiva de diversos usos do termo. É o caso, por exemplo, do artigo de Karla Bessa (2007, p. 257-283), para a revista Cadernos Pagu. 
ficados variados conforme cada contexto, de modo que suas significações parecem se misturar e se confundir dentro dos mesmos textos e discursos. Reconhecendo tanto esse desafio quanto as contribuições de perspectivas dos estudos feministas para compreender diferentes noções de representação, Rabenhorst e Camargo sugerem, de forma didática, abordar três variações que identificaram como mais recorrentes e que podem ser correlacionadas:

(1) representação social, que remete à representação do próprio feminismo enquanto movimento social e político; (2) representação política, que compreende as discussões acerca da identidade entre o sujeito que representa e os interesses das pessoas representadas, bem como o complexo modelo de representação que busca tornar presente aquilo que está ausente; (3) representação estética, que abrange as discussões da representação no campo da arte (RABENHORST; CAMARG0, 2013, p. 986).

0 presente artigo concentra-se na terceira forma de representação entre as sugeridas pelos autores, problematizando-a a partir de leituras específicas em estudos de imagem, cinema e publicidade. De acordo com os mesmos autores, a noção de representação pressupõe uma distância entre o objeto representante e o objeto representado, no que consiste sua razão de ser. Uma representação idêntica ao objeto ou efetivamente capaz de substituí-lo seria simplesmente sem função. Nisso, eles realçam a ideia de abordar a representação em um sentido ficcional, como seria, segundo os mesmos, utilizada pelos juristas na origem do termo (RABENHORST; CAMARG0, 2013, p. 984).

Em outra análise, própria dos estudos de cinema e, mais especificamente, do cinema documentário, Menezes afirma que "um filme não é uma representação do real, pois a representação não se confunde com o próprio real" (MENEZES, 2003, p. 90). Ele também destaca que nas artes, em princípio, a representação não era avaliada em termos de sua parecença com o que seria o objeto real, sendo que a aproximação entre representação e realidade teria se instaurado no Ocidente a partir da constituição das ciências durante o Renascentismo e da preocupação de representar fidedignamente desde a anatomia humana a paisagens, texturas e noções de profundidade.

Ambas as perspectivas, embora em chaves e contextos analíticos diferentes, apontam o principal problema dos debates envolvendo a representação e que emerge de forma bastante relevante em trabalhos de estudos de gênero: as relações entre a representação e a realidade supostamente representada. Destarte, ao problematizar a noção de representação, este artigo consiste, mais do que numa revisão de conceitos e categorias analíticas, em questionar as próprias percepções de realidade mobilizadas nos usos desse termo, cujo debate se revela significativo em diferentes áreas de estudo e interesse das ciências humanas, por vezes suscitando polêmicas e contradições. Mais ainda, quando se trata de uma abordagem sociológica de produções cinematográf1cas e audiovisuais, acredita-se ser possível elaborar análises consistentes sem recorrer aos vícios e armadilhas do termo representação. 0 termo frequentemente assume entendimentos conflituosos que colocam no centro a sua relação com a realidade. Conforme Aumont e Marie:

Utilizada em numerosos e variados contextos, a palavra [representação] designa sempre uma operação pela qual se substitui al- 
guma coisa (em geral ausente) por outra, que faz as vezes dela. Este substituto pode ser de natureza variável: uma imagem (representação pictórica, fotográfica, cinematográfica), uma performance em um palco (representação teatral), etc. [...] No que concerne à representação por imagens, a questão principal foi, no mais das vezes, a de decidir se ela punha em jogo atitudes humanas inatas e universais, ou, ao contrário, atitudes culturais, adquiridas e particulares (AUMONT; MARIE, 2009, p. 255-256).

Judith Butler (2013) critica noções diversas sobre representação no sentido de estas, muitas vezes, pressuporem a existência de uma figura feminina (mulher) "natural" e "universal" anterior a qualquer representação, sendo suas representações construídas culturalmente, com funções específicas de manutenção de uma estrutura de dominação e controle. Conforme a autora aponta:

0 próprio sujeito das mulheres não é mais compreendido em termos estáveis ou permanentes. É significativa a quantidade de material ensaístico que não só questiona a viabilidade do "sujeito" como candidato último à representação, ou mesmo à libertação, como indica que é muito pequena, afinal, a concordância quanto ao que se constitui, ou deveria constituir, a categoria mulheres. Os domínios da "representação" política e linguística estabeleceram a priori o critério segundo o qual os próprios sujeitos são formados, com o resultado de a representação só se estender ao que pode ser reconhecido como sujeito. (BUTLER, 2013, p. 18)

Em algumas das noções por ela criticadas, é perceptível a influência de leituras marxistas, quando a realidade é percebida como o antagonismo de classes e sua relação de dominação encoberta pela névoa da ideologia - onde operaria a representação constituindo ilusões que servem exclusivamente à manutenção do sistema vigente de exploração. Neste aspecto, quanto aos modelos de feminilidade apresentados na mídia, Heloísa Buarque de Almeida discorre:

Por um lado, durante os anos 70 principalmente, discutiu-se que os modelos femininos mostrados na mídia não corresponderiam às mulheres reais (ou à realidade das mulheres no cotidiano) ou teriam o compromisso ideológico de modelos e papéis femininos circunscritos à dominação patriarcal da sociedade. Tais concepções sobre o estatuto dos meios de comunicação na manutenção da dominação patriarcal eram muitas vezes influenciadas pela reflexão da Escola de Frankfurt sobre o poder da indústria cultural. Sob essa ótica, os trabalhos questionavam a representação feminina nos programas e anúncios publicitários, e demandavam inclusive que se mostrasse mulheres "mais realistas”, em suas atividades profissionais, por exemplo, de acordo com sua presença e atuação na sociedade (ALMEIDA, 2006, p. 16).

Lauretis, por outro lado, deixa clara sua perspectiva ao afirmar como uma de suas premissas básicas que "gênero é representação - o que não significa que não tenha implicações concretas ou reais, tanto sociais quanto subjetivas. Muito pelo contrário" (LAURETIS, 1994, p. 208). A premissa seguinte é de que a "representação de gênero é sua construção” (p. 208). Essa abordagem já se aproxima mais da crítica suscitada por Butler, no sentido de que a representação de gênero não se distanciaria da realidade, mas, ao contrário, contribuiria relevantemente para constituir e reiterar 
diferenças de gênero. Como Butler, a autora também parece recusar a existência de um sexo feminino "natural" biologicamente pré-estabelecido, reconhecendo o gênero a partir da diferenciação cultural e historicamente constituída entre masculino/feminino, a qual ela, amparando-se também em Foucault, trata como desdobramento de uma "complexa tecnologia política" (FOUCAULT apud LAURETIS, 1994, p. 207).

Assim, Lauretis torna complexo o debate sobre gênero e representações e, em sua análise, propõe o cinema como sendo uma das várias "tecnologias de gênero [...] com o poder de controlar o campo do significado social e assim produzir, promover e 'implantar' representações de gênero" (LAURETIS, 1994, p. 228). A questão aqui se torna mais abrangente, sendo a produção cinematográfica entendida como um aparato tecnológico entre outros, voltado à produção de uma representação com funções políticas de reificar ideologias relacionadas a gênero e com implicações práticas e concretas significativas.

Apesar de aprofundar o debate sobre representação e suas implicações na vida e experiência femininas, Lauretis parece ainda, em alguns momentos, pautar-se pelo antagonismo entre realidade e representação ao mesmo tempo em que tenta recusá-lo, atribuindo à segunda aspectos ideológicos que atuariam como uma cortina que insiste em se colocar sobre a "verdadeira" realidade, onde a diferenciação sexual e sua manutenção serviriam à preservação de uma estrutura social de caráter liberal burguesa, dominada pelo patriarcado. A autora é categórica ao se referir a "óbvios exemplos de representação ideológica do gênero no cinema, onde a intencionalidade da tecnologia é virtualmente colocada em primeiro plano na tela” (LAURETIS, 1994, p. 232). No limite, seria possível afirmar que há uma "intencionalidade" predeterminada da tecnologia, destinada a um cálculo minuciosamente planejado de manutenção da ideologia? Quanto dessa "representação ideológica”, tão sedimentada no imaginário e nas crenças estabelecidos em sociedades patriarcais e heterossexistas não transcendem a intencionalidade, tanto de produtores quanto de atores e espectadores, cujas percepções naturalizadas não os tornam, por vezes, involuntariamente, reprodutores dessa condição? Contudo, Lauretis sugere a possibilidade de não negar as representações em si, que ela assume como elementares às construções de gênero. A autora apontaria então a possibilidade de dar visibilidade a outras formas possiveis de representação, eclipsadas pelo discurso hegemônico:

...o movimento para dentro e fora do gênero como representação ideológica, que, conforme proponho, caracteriza o sujeito do feminismo, é um movimento de vaivém entre a representação de gênero (dentro de seu referencial androcêntrico) e o que essa representação exclui, ou, mais exatamente, torna irrepresentável. É um movimento entre o espaço discursivo (representado) das posições proporcionadas pelos discursos hegemônicos e o space-off, o outro lugar, desses discursos: esses outros espaços tanto sociais quanto discursivos, que existem, já que as práticas feministas os (re)construíram, nas margens (ou "nas entrelinhas" ou "ao revés"), dos discursos hegemônicos e nos interstícios das instituições, nas contrapráticas e novas formas de comunidade. Esses dois tipos de espaço não se opõem um ao outro, nem se seguem numa corrente de significação, mas coexistem concorrentemente e em contradição (LAURETIS, 1994, p. 238). 
As implicações políticas do termo representação, mesmo para tratar de imagens e narrativas audiovisuais se tornam evidentes. Percebe-se nas discussões que antagonizam representação e realidade, muitas vezes a busca pela constituição de um sujeito político, de reivindicações bem defınidas, uma categoria que seria capaz de "unificar" um conjunto profundamente heterogêneo e difuso de reinvindicações igualmente diversas, criando sua representação mais completa, capaz de se posicionar coletivamente, conscientizar-se de sua condição comum e, a partir dela, combater a representação hegemônica. No entanto, o conceito de representação suscita embates importantes do ponto de vista político: "As dificuldades de representar a mulher implicam diretamente na fragilização do sujeito político dos movimentos feministas, pois se a mulher não pode ser representada, fica difícil identificar com nitidez o que seriam as reivindicações 'feministas”" (RABENHORST; CAMARGO, 2013, p. 996). Rabenhorst e Camargo também concluem que a questão da representação nos estudos feministas parece necessariamente passar pela questão da imagem, sendo esta, em muitos casos, utilizada superficialmente como sinônimo de representação.

Por essas razões, considera-se relevante suscitar outras abordagens possíveis não acerca das representações - políticas, artísticas, sociais -, mas de estudos de imagens que se desvencilhem da polissemia das "representações” e permitam uma discussão aprofundada de seu uso e relevância para abordar sociologicamente questões de gêneros numa dupla chave, tanto como construções específicas, que se utilizam de técnicas, linguagens e signos específicos, como de sua relação social com outras imagens, discursos, noções e percepções compartilhados e reconhecidos no senso comum.
Rechaça-se aqui qualquer perspectiva de comparação entre o "real" e suas imagens, priorizando relações socialmente constituídas com imagens e entre imagens que são culturalmente construídas e transformadas, permitindo ou limitando o reconhecimento dessas imagens em suas conexões mais amplas com visões de realidade presentes no senso comum e continuamente (re)ajustadas. Nesse sentido, ao pensar o problema em termos de relações sociais entre imagens, considera-se aqui mais de um século de cultura cinematográfica acrescida de outros aparatos tecnológicos - de videocassetes a telefones celulares com câmeras - e como se constituíram e se constituem formas de ver, estar e comunicar no mundo, integrando à vida cotidiana essas imagens e tomando-as referências para práticas, comportamentos e expressões da subjetividade.

\section{Imagens da realidade: outros olhares possíveis}

Walter Benjamin afırmara, ainda em 1936 que:

No decorrer dos grandes períodos históricos, com relação ao meio de vida das comunidades humanas, via-se, igualmente, modificarse o seu modo de sentir e de perceber. A forma orgânica que é adotada pela sensibilidade humana - o meio na qual ela se realiza não depende apenas da natureza, mas também da história (BENJAMIN, 1975, p. 14).

Ao se levar em conta essa perspectiva, em conjunto com as rápidas transformações por que passaram os meios de comunicação de massa, especialmente a partir da segunda metade do século XX, essas mudanças nos modos "de sentir e perceber" têm decorrido não em grandes perío- 
dos históricos, mas muitas vezes dentro do interstício de uma mesma geração. As transformações tecnológicas no campo de transmissão de imagens e informações nos últimos anos têm levado gerações inteiras a reconfigurar seus olhares perante à realidade, de modo a, frequentemente, contrapor e questionar os próprios modos estabelecidos como "naturais". Isso se percebe nas relações diferenciadas de gerações que atingiram a idade adulta antes da expansão das mídias digitais e a popularização de aparelhos de telefonia celular e tablets, hoje vastamente utilizados para produção, reprodução e transmissão de vídeos. Assim como o cinema no início do século XX contribuiu significativamente para novas formas de olhar, a partir de uma grande tela em uma sala com projeções para centenas de espectadores em um mesmo auditório, a televisão, ao adentrar o universo privado também constituiu mudanças. De outro modo, a telefonia móvel hoje permite outras formas de olhar e se relacionar com produções audiovisuais - do transporte público a salas de espera, as possibilidades são incontáveis. Nesse sentido, não é absurdo deduzir que as formas de sentir e perceber relacionadas a categorias e normas de gênero, bem como às práticas sexuais são modificadas e, com isso, sociabilidades, formas de agir e se comunicar que superariam a suposta passividade atribuída ao espectador.

A relação entre imagem e realidade problematizada por Menezes (2003) mais especificamente do cinema documentário, discute seu caráter igualmente ficcional, diferenciado somente por uma "leitura documentarizante" que pressupõe um "enunciador real” (ODIN apud MENEZES, 2003, p. 91). Ao abordar os limites e as construções da realidade do cinema documentário,
Menezes questiona o uso da noção de representação na análise fílmica e propõe o conceito de representificação:

Proponho que se entenda a relação entre cinema, real e espectador como uma representificação, como algo que não apenas torna presente, mas que também nos coloca em presença de, relação que busca recuperar o filme em sua relação com o espectador. 0 filme, visto aqui como filme em projeção, é percebido como uma unidade de contrários que permite a construção de sentidos. Sentidos estes que estão na relação, e não no filme em si mesmo. 0 conceito de representificação realça o caráter construtivo do filme, pois nos coloca em presença de relações mais do que na presença de fatos e coisas. Relações constituídas pela história do filme, entre o que ele mostra e o que ele esconde. Relações constituídas com a história do filme, articulação de espaços e tempos, articulação de imagens, sons, diálogos e ruídos (MENEZES, 2003, p. 94 - grifo nosso).

A despeito das especificidades da análise proposta pelo autor para o cinema documentário em seu argumento, um elemento que merece destaque é o foco nas relações constituídas tanto dentro da própria narrativa fílmica, enquanto construção de sentido, quanto com "o trabalho de nossas memórias voluntária e involuntária que o filme estimula" (MENEZES, 2003, p. 94). Pensar sociologicamente esse aspecto relacional de um filme, especialmente quando se trata do estímulo de memórias dos espectadores, implica pensar em relações entre imagens, muitas vezes, mais do que entre imagem e experiência. Há que se considerar também, que, ao sublinhar o caráter construtivo do filme, as imagens nele constituídas, sejam de homens, mulheres, 
heróis, vilões, períodos históricos, classes ou países não se propõem tanto a "representar" uma realidade externa preexistente, mas, ao contrário, constituem uma realidade própria via conexões de sentido, tanto diegeticamente quanto em relação aos espectadores e sua bagagem cultural, social e afetiva. Nesse sentido, reforça-se aqui, para a análise sociológica de filmes, pensar relacionalmente as imagens enquanto construções de sentido, não limitadas ao espaço da tela e nem ao tempo do filme.

$\mathrm{Na}$ atual e constante presença de produtos de mídias audiovisuais e digitais no cotidiano, a relação com o espectador se dá, em grande medida, entre imagens às vezes visualizadas anteriormente ou simplesmente aludidas. Tal relação é mais evidente no cinema hollywoodiano, repleto de autorreferências e repetidas estratégias narrativas que se tornam familiares e reconhecíveis como típicas, desde os usos da trilha sonora - que se desdobra em outro produto de merchandising que extrapola a projeção do filme, mas persiste enquanto relação e alusão -, aos movimentos de câmera, planos e cortes para cada tipo de cena que se pretende: do encontro do grande amor à resolução de um enigma ou à vitória em uma competição esportiva. Frequentemente, a repetição dessas construções em diferentes narrativas, enquanto "pontos de fixação" (SORLIN, 1982, p. 236) constitui uma relação peculiar com os espectadores que é muito pouco pautada necessariamente por suas experiências num sentido mais "concreto". Isso é especialmente notável quando se trata do cinema hollywoodiano, que frequentemente se apresenta a seu público como uma espécie de linguagem "universal", consumida e apreciada em diversos países, independentemente da correspondência entre as suas práticas e possibilidades cotidianas e aquelas visualizadas nos filmes.
Em seus estudos sobre pintura, Gombrich (2007) já apontara a importância de se compreender as imagens a partir de relações, tanto das formas empregadas dentro da pintura, o uso das luzes e cores quanto em relações mais amplas com outras imagens e com convenções existentes dentro do campo artístico que, não raramente, pouco se propõem à finalidade de parecença ou reprodução "fidedigna" de qualquer realidade. Contudo, os adventos da fotografia e, posteriormente, do cinema, parecem complicar essa relação. Enquanto invenção moderna, num contexto de valores já bem estabelecidos culturalmente no Ocidente de olhares cientificistas, pretensamente "neutros" e "realistas", a fotografia, enquanto registro mecânico do que se passa à frente da câmera, parece embaraçar ainda mais essa relação entre imagem e realidade, sendo assumida, frequentemente não como construção, mas como documento que porta em si o estatuto de realidade. Tendo essa relação em vista, pensando o surgimento do cinematógrafo não como fonte de entretenimento, mas como aparato mecânico de registro de luz e movimento, a questão da realidade das imagens parece ainda mais impregnada. Nesse sentido, ainda há uma tendência comum em relação ao cinema de se avaliar a qualidade de um filme em termos de sua suposta proximidade com a realidade. Nas palavras de Marcel Martin:

A imagem fílmica restitui exata e inteiramente o que é oferecido à câmera e o registro que ela faz da realidade constitui, por definição, uma percepção objetiva: o valor probatório do documento fotográfico ou filmado é um princípio irrefutável, ainda que sejam possíveis truques [...]. A imagem fílmica, portanto, é antes de tudo realista, ou, melhor dizendo, dotada de todas as aparências 
(ou quase todas) da realidade. [...] A imagem fílmica suscita, portanto, no espectador, um sentimento de realidade bastante forte, em certos casos, para induzir à crença na existência objetiva do que aparece na tela. Essa crença, essa adesão, vai das reações mais elementares [...] aos fenômenos bem conhecidos de participação (os espectadores que advertem a heroína dos perigos que a ameaçam) e de identificação com os personagens (MARTIN, 2003, p. 22).

No caso de filmes declaradamente ficcionais - lembrando que, de acordo com Menezes (2003, p. 94), o cinema documentário também seria uma forma de ficção -, parece haver a crença de que as imagens não necessariamente "reproduzam" alguma realidade, mas, no sentido mais corrente do termo discutido aqui, de que representam alguma realidade, balizadas pela noção de parecença, no que muitos presumem que o objetivo primordial da imagem fílmica seja se tornar indiscernível da realidade. Supondo que se aceite tal hipótese, o que permite ao cinema hollywoodiano - com características que lhe são tão peculiares quanto restritas no que diz respeito à aparência de seus protagonistas, ao encadeamento de suas narrativas e discursos -, tenha tamanha presença ao redor de um mundo de espectadores completamente heterogêneo? Cabe questionar inclusive se, sequer mulheres norte-americanas de classe média, caucasianas, heterossexuais, em casamentos monogâmicos se considerariam satisfatoriamente "representadas" nas personagens femininas construídas em filmes hollywoodianos e caracterizadas como tais. Enxergariam elas, necessariamente, "imagens realistas" de si mesmas? Mais pertinente: deveriam enxergar?

Pensar as produções cinematográficas a partir de uma relação direta - e mais ou menos antagônica - com a realidade incorre invariavelmente em constatações de que "a realidade é muito diferente", o que, frequentemente, é utilizado em críticas a pesquisas em ciências sociais que têm por objeto essas produções. Nesse sentido, ao tratá-las como representações da realidade, automaticamente atribuem-lhe falsidade, tornando-as cientificamente "sem validade". Frequentemente, recusa-se o filme como objeto de análise, a ser "legitimado" apenas através da pesquisa de campo e, em outras vezes, pelo registro de imagens pelo próprio pesquisador, previamente mediado por uma pretensa posição de "olhar científico" contraposto às "imagens de ficção".

Alguns entenderiam que a melhor solução estaria nos estudos de recepção. Mas sendo a recepção profundamente subjetiva, uma vez que, de acordo com o conceito de representificação, o filme, durante sua projeção, comunicaria com memórias voluntárias e involuntárias do espectador - no que se inclui, não raramente, memórias afetivas - como se superaria satisfatoriamente o problema da heterogeneidade se a subjetividade dos entrevistados lhes conduzisse a experiências do filme consideravelmente diferentes? Esquematizar isso em forma de entrevista também não seria profícuo, posto que a formulação das questões, na tentativa de aferir impressões dos espectadores sobre o filme determinadas pelo pesquisador lhes obrigaria a resgatar de forma direcionada sua memória para os aspectos suscitados no questionário, com o potencial de induzir o espectador a respostas não baseadas em suas impressões mais espontâneas, mas em uma reinterpretação do filme à luz do questionário, bem como de sua experiência ao assistir o filme. Nesse sentido, questionários, muito facilmente, induziriam a certos tipos de respostas que escapariam de seu 
propósito original, ao estimular o espectador a repensar o filme e reelaborar sua interpretação para codificá-la de acordo com o que é demandado pelo pesquisador.

Reconhecendo os limites de acesso não somente à subjetividade de cada espectador, como a cada uma de suas experiências singulares, a chave para a compreensão da relevância sociológica das mídias audiovisuais repousaria em seu aspecto comunicativo e linguístico, ao mobilizarem signos e discursos cognoscíveis para um público diversificado. Trata-se, efetivamente de, seguindo uma inspiração weberiana, buscar os sentidos mobilizados e compartilhados na construção dessas imagens que não se restringem à unidade da narrativa fílmica, suscitando outras imagens, discursos, tramas e recursos técnicos de outras fontes, reutilizados, relembrados, sistematicamente reiterados e reconfigurados ao longo de mais de um século de cultura cinematográfica.

Um filme, no processo de representificação, efetivamente se comunicaria com memórias voluntárias e involuntárias por estabelecer uma relação que não é exclusiva com o espectador enquanto portador de uma história de vida particular, mas mediada por outras imagens e referências que interpenetram sua existência tanto individual quanto social. Trata-se, de forma mais específica, de uma relação constituida entre imagens, ou seja: entre construções que encontram suas primeiras referências precisamente dentro de um vasto inventário de imagens que são, na prática, indissociáveis de relações e experiências cotidianas dos espectadores. Estes não apenas não se encontram passivamente expostos a essas imagens, como as interpretam, ressignificam e as mobilizam em suas interações. Parte considerável desse inventário está à disposição dos espectadores em diferen- tes formatos e variáveis possibilidades de acesso - da sessão de cinema à reprodução de vídeos via internet - e assim permanece além da experiência individual. A relação primeira estabelecida aqui, em seus aspectos socioculturais, é no nível do imaginário e transcende a materialidade a que muitos tendem a reduzir a realidade. As imagens do cinema, da televisão e das campanhas publicitárias encontram seu nexo na possibilidade de relação com outras imagens mais do que necessariamente com "coisas".

Ao se considerar aqui a atual presença de diferentes dispositivos de reprodução e difusão de vídeos, bem como as relações construídas entre imagens, é importante sublinhar que estas não se limitam a uma ou outra mídia específica: telenovelas fazem referências a construções cinematográfıcas, vídeos publicitários por vezes fazem referências a desenhos animados, filmes exploram imagens de telejornais mescladas à narrativa, programas de variedades e auditório utilizam, conforme o quadro e as circunstâncias, músicas-tema de determinados filmes e assim por diante. As imagens e construções fílmicas, portanto, de formas diversas, combinam-se e transformam-se enquanto aparatos de linguagem os quais, por sua vez, têm uma existência que, embora dependente da ação de indivíduos para sua manutenção, não é exclusivamente subjetiva. Nesse sentido, a linguagem exerce um papel de objetivação:

A expressividade humana é capaz de objetivações, isto é, manifesta-se em produtos da atividade humana que estão ao dispor tanto dos produtores quanto dos outros homens, como elementos que são de um mundo comum. Estas objetivações servem de índices mais ou menos duradouros dos processos subjetivos de seus produtores, permitindo 
que se estendam além da situação face a face em que podem ser diretamente apreendidas. [...] Estou constantemente envolvido por objetos que "proclamam" as intenções subjetivas de meus semelhantes, embora possa às vezes ter dificuldade de saber ao certo o que um objeto particular está "proclamando", especialmente se foi produzido por homens que não conheci bem (BERGER; LUCKMANN, 1983, p. 54-55).

Conforme Mills (2009, p. 66) apontara, "vivemos em realidades de segunda mão", onde boa parte de nosso conhecimento é mediada por diferentes aparatos de comunicação e informação que transcendem a experiência pessoal: das fotografias em jornais impressos a vídeos compartilhados instantaneamente na internet. É cada vez mais evidente nas sociedades contemporâneas a construção da realidade e das experiências como objetivações a partir de imagens, as quais proclamam mais que intenções subjetivas, enunciando acontecimentos, posicionamentos políticos, normas comportamentais e, inclusive, normas de sentimentos.

0 ponto marcante nas discussões sobre representações de gênero na arte, no cinema, na televisão e na publicidade, é que essas teriam efeitos diretos na vivência cotidiana dos espectadores, nas formas com que constituem identidades, posturas e comportamentos, bem como a forma com que interpretam o mundo à sua volta e se posicionam em relação a ele. Tais efeitos não derivam de nenhuma espécie de influência externa, mas de fazerem parte de como os indivíduos se comunicam diariamente e fazem indicações aos outros e a si mesmos, tanto dos mundos à sua volta quanto de sua subjetividade. Entretanto, frequentemente o debate se coloca sobre a necessidade de produzir representa- ções "mais reais" ou denunciar a irrealidade das imagens, mantendo um binarismo que insiste em opor imagem e realidade. Ao lançar um olhar mais atento, notam-se duas inconsistências que desmontam essa perspectiva: a primeira é a que insiste em separar "imagem" e "realidade" ou "imagem" e "experiência”, ignorando suas interpenetrações, especialmente na constituição de relações de sentido que, por sua vez, orientam formas de agir, de se posicionar e se apresentar; a segunda se refere ao fato de que, muitas vezes, não é propósito de muitas dessas imagens reproduzir, retratar, ou refletir qualquer realidade. Pensar conforme a chave dicotômica de representação (imagem) vs. realidade (experiência) gera um debate inócuo de constatações óbvias, onde a primeira nunca corresponde à última.

A questão aqui, mais do que escapar da dicotomia entre representação e realidade, é superá-la e colocar em relevo a importância das imagens e produções audiovisuais em seu aspecto de construção e difusão de sentidos que, por sua vez, se concretizam em ações sociais, em condutas orientadas pelo reconhecimento e partilha dos significados propagados também através de imagens. Especialmente no contexto atual de grande parte das sociedades urbanas modernas, as mídias fundamentadas no uso de imagens têm presença abrangente, constituindo formas de compreender o mundo, reconhecê-lo e aludi-lo. Alusões que se baseiam, em grande medida, em imagens massivamente compartilhadas que, por sua vez, fazem referências a outras anteriormente difundidas.

Essas relações constituídas entre imagens são, ao mesmo tempo, produtoras e produto dessa realidade da qual muitos insistem em descolar suas representações pictóricas. Por isso, entende-se que a repetição 
do uso do termo representação é problemática. Não se trata simplesmente do uso de uma palavra entre tantas outras possíveis; buscar sinônimos não resolve o problema. Trata-se, efetivamente, de problematizar os olhares, as linhas de raciocínio, as conexões de sentido e concepções de realidade e imagens que esse termo, em toda sua polissemia, suscita. Mais do que trocar uma palavra por outra, trata-se de pensar em termos de uma construção, que se materializa constantemente pelo resgate, a reiteração e a transformação dos próprios signos que a fundamentam.

Entende-se que, com a devida mediação - colocando o termo em questão ao invés de naturalizá-lo -, e as considerações pertinentes, não haveria razão para não utilizar o termo representação. Aliás, Stuart Hall (1997, p. 24), apresenta contribuições importantes no sentido de problematizar as noções de representação que ele denomina como reflexiva, intencional e construcionista apontando diferentes panoramas de "representação" em estudos culturais, apresentando tanto fragilidades quanto pontos fortes desses panoramas, como integrantes de um "conjunto complexo e ainda experimental de ideias em um projeto inacabado" (p. 63). Contudo, muitos autores não explicitam as formulações conceituais ou metodológicas do termo, enquanto que, muitos de seus leitores não familiarizados com o debate, tendem a lê-lo em chaves que se aproximem do senso comum. Assim, constituem-se textos e leituras naturalizadas de representação contraposta à realidade, onde, supostamente, a primeira "deveria" ser mais fiel à última, mas não o é "apenas" porque determinados grupos atuam, conspiratória e incansavelmente no sentido de ocultar essa realidade. Acaba-se, deste modo, por desconsiderar importantes aspectos de construção cultural e social, am- parados no recurso a imagens que é mútua e, frequentemente, não calculada por seus agentes. E nisso, desdobra-se a importante problemática das imagens enquanto matéria -prima consistente na construção da realidade social em sua dimensão comunicativa.

\section{Imagens do feminino ou o intangível objetivado}

É reconhecida a importância política de se colocar em questão quais construções de gêneros são frequentemente suscitadas, remarcadas e repetidas nas relações que se estabelecem socialmente entre imagens. É de suma importância dar visibilidade a construções alternativas, romper a hegemonia das construções que já se tornaram naturalizadas e que, frequentemente, são confundidas com retratos, senão da realidade do que um gênero supostamente "é", mas, de forma mais contundente, do que um gênero "deveria ser" para que tenha sua existência legitimada e reconhecida. Concorda-se neste ponto com Lauretis que as implicações das imagens e produções cinematográficas enquanto "tecnologias de gênero" são concretas à medida que promovem e reforçam discursos que são recebidos, reconhecidos e internalizados na formação de comportamentos e na construção de noções identitárias do público, sendo ainda empregadas como indicadores da própria subjetividade. Mas essas imagens, enquanto "tecnologias de gênero", apenas reforçam o quanto é falho pensar em termos de uma separação entre imagem e realidade quando as práticas, as visões e os discursos de gênero se constituem com base nas interpretações de conexões diversas de sentidos de imagens entre si.

Assumir uma realidade em oposição ou à parte dessas imagens equivale a posicio- 
namentos essencialistas como, por exemplo, pressupor a existência biologicamente "natural” e binária dos sexos, pré-social, universal e anterior à cultura na qual gênero e sexualidade são constituídos e inscritos. E, na busca insistente por uma representação "real" da mulher no cinema, na televisão ou na publicidade, o que tem se revelado é apenas a diversidade irredutível a qualquer representação unívoca. No caso do cinema, que, conforme Morin (2002), funciona em grande medida à base de sínteses - que pressupõem a reunião de contradições sabidamente inconciliáveis dentro de uma unidade condensadora esperar das imagens ou projetar nelas um realismo abrangente seria despropositado. Ao abordar o amor na cultura de massas, Morin aponta esse aspecto:

Nesse amor sintético a mulher tende a aparecer simultaneamente como amante, companheira, alma-irmã, mulher-criança e mulher-mãe e o homem como protetor e protegido, fraco e forte. A eliminação dos temas familiares ou incestuosos no cinema ocidental implica sua integração latente na relação entre os dois namorados. Em outras palavras, é a totalidade dos laços afetivos, antigamente repartida em múltiplas relações intrafamiliares que tende a se concentrar no casal (MORIN, 2002 p. 134).

A condensação e a síntese são elementos fundamentais da narrativa cinematográfica e seu estatuto de realidade é puramente convencional, por mais que ela se sustente pelo convencimento que provoca enquanto sequência apreensível de eventos e articulação de imagens e sons mecanicamente captados. Mas as convenções que a orientam extrapolam a produção fílmica e se comunicam com diversas outras, in- cluindo todas aquelas que se referem a performances de gêneros e que se entrecruzam em diversos cenários da vida cotidiana: de instituições religiosas a ambientes de trabalho, do espaço público à orientação da vida afetiva e dos espaços privados. A síntese tem importante papel compreensivo no cinema ao estabelecer conexões lógicas de causa e consequência entre elementos selecionados, realçando algumas variáveis em relação a outras e criando uma legibilidade que se pauta menos pela realidade do que pela associação lógica entre os eventos dentro do filme. Isso implica dizer que a representação é sempre redutora.

Há que se ponderar também a noção de "cultura de massa" enquanto algo que se apresentaria como geral e homogêneo, contribuindo para as percepções críticas dos conteúdos difundidos por tal cultura. Equiparar em uma "massa" - que pressupõe uniformidade - um conjunto de consumidores e espectadores totalmente disperso e heterogêneo, incorre, logicamente, no obscurecimento das diferenças. 0 problema gira, em grande parte, em confiar, de forma acrítica, na homogeneização das imagens propagadas pela "cultura de massas" e, frequentemente, confundi-las com uma homogeneização da realidade de forma mais ampla. Sobre a noção de cultura de massas, Passerini faz uma observação interessante para analisá-la em termos de potencialidade:

Chamamos a atenção para o fato de que eles [os termos "massa" e "de massa"] têm um valor no plano das potencialidades; devemos acrescentar que não se referem apenas no uso corrente, a aspectos quantitativos, mas também a aspectos qualitativos. Queremos com isso dizer que a cultura de massas não é produzida por intelectuais e que é destinada a uma massa social, ou seja, a um aglo- 
merado aparentemente não diferenciado em classes e áreas geográficas. Ao lado das culturas clássicas, radicadas num povo particular, a nova forma cultural parece nascida dos meios de comunicação de massa, sem raízes locais defınidas (PASSERINI, 1991, p. 395).

Há que se considerar essa própria "massa” - a que tal forma cultural se direcionaria - como algo imaginário, enquanto categoria abrangente inventada, a partir da qual a segmentação da produção cultural para o grande público ver-se-ia facilitada. Nesse sentido, pensa-se a potencialidade aqui não em termos de características pretensamente "objetivas" (renda, idade, escolaridade, classe, sexo) de grupos de receptores, mas em termos de possibilidades de apreensão e reconhecimento da linguagem e dos sentidos suscitados nos conteúdos difundidos através das diferentes mídias comunicadoras. Trata-se aí do potencial de reconhecimento não somente das imagens, mas de suas cargas culturais e valorativas. Estas não emergem espontaneamente das imagens, mas são imbuídas em sua formação através da relação com outras imagens e discursos, evocadas ou suprimidas em interações sociais. Por isso, uma imagem é, de certa forma, sempre dependente de outra, como palavras em um enunciado, cujo sentido depende das formas como estas são conectadas umas às outras e das construções de sentido que cada uma carrega em função de convenções linguísticas. E, invariavelmente, as imagens, enquanto aparato comunicativo, dependem de indivíduos interagindo para que se mantenham circulantes, reativando e realçando as convenções a que estão atreladas.

Pensar as construções de gênero a partir de imagens circulantes em meios de comunicação, dentro da perspectiva aqui pro- posta, não seria pensar a noção de gênero como separada de sua imagem, uma vez que, concordando com Butler (2013), gênero seria uma categoria constituída performativamente, entre gestos e discursos não necessariamente coerentes entre si. Ainda conforme a autora:

A performatividade não é, assim, um "ato" singular, pois ela é sempre uma reiteração de uma norma ou conjunto de normas. E na medida em que ela adquire o status de ato no presente, ela oculta ou dissimula as convenções das quais ela é uma repetição. Além disso, esse ato não é primariamente teatral; de fato, sua aparente teatralidade é produzida na medida em que sua historicidade permanece dissimulada (e, inversamente, sua teatralidade ganha uma certa inevitabilidade, dada a impossibilidade de uma plena revelação de sua historicidade) (BUTLER, 2000, p. 161).

Essa repetição das convenções, mesmo em seu nível individual, reitera normas que se tornam reconhecidas e compartilhadas tanto pelas práticas e interações cotidianas quanto pela incorporação dos conteúdos dessas normas, insistentemente reforçados pela mídia cinematográfica e outras baseadas em imagens.

Assim, as imagens não são nem retrato, reprodução, representação ou reflexo da realidade, mas elementos de sua própria construção, participando de [trans]formações e reiterações de "noções culturalmente inteligíveis de identidade de gênero" (BUTLER, 2013, p. 23), elementos estes que muitas vezes são apresentados e percebidos de forma aglutinadora, propondo-se unificadores e assim, devidamente articulados com noções binárias de sexo e discursos heteronormativos e biologizantes nela impregnados. A partir da maior visibilidade concedida a 
algumas imagens do que a outras, via insistente e difundida repetição, calcificam-se determinadas formas se reconhecer e produzir noções de gêneros que facilmente se amparam no poder quase mágico de convencimento da fotografia e do cinema. Ainda assim, as atuais circunstâncias têm ampliado o contato com a diversidade também para imagens de gênero e temáticas relacionadas à sexualidade. Conforme Louro:

Uma série de condições culturais, sociais, políticas, econômicas vem, desde algumas décadas possibilitando a multiplicação dos discursos sobre a sexualidade, produzindo a visibilidade das muitas formas de ser, de amar e de viver, embora se mantenham, de modo renovado, divisões, hierarquias, diferenciações. 0 cinema participa também deste processo (LOURO, 2008, p. 87).

As imagens aqui são entendidas como elementos de linguagem, no que há ainda uma série de especificidades ao se considerar seus diferentes usos, textos e contextos. Fotografias, filmes, desenhos animados, jogos eletrônicos, medicina diagnóstica; todos estes têm sua interpretação orientada por convenções que lhes são peculiares, constituindo leituras diferenciadas da realidade, para as quais o olhar se configura correspondentemente, no que o leitor resgata em sua memória informações, outras imagens, experiências e aprendizados, combinando todo o aparato necessário para que ele consiga interpretar aquelas imagens. Nada disso, contudo, garante interpretações puristas de um sentido univocamente "correto" ou mais "realista". É então o caso de buscar as relações "tornadas importantes" (WEBER, 2008, p. 34) entre imagens para que se produzam determinadas interpretações e, consequentemente, ações por elas orientadas.
Tem-se em vista que as imagens fotográficas e cinematográficas exercem um fascínio particular, uma vez que, por serem produzidas a partir do manuseio de um aparato mecânico que registra o que se apresenta à sua frente de forma aparentemente neutra, supostamente capturaria a realidade "objetivamente", livre de julgamento, posicionamento moral e/ou afetivo de quem está por trás da câmera. Essa forte impressão de realidade, mais do que mobilizar necessariamente uma crença imediata no que é apresentado como produto da câmera, mobiliza parâmetros visuais de realidade, convencionando formas de vê-la e avaliá-la dentro e fora das telas. Certamente, esse é um elemento cultural fundamental nos posicionamentos variados e conflitantes que se produziram sobre a relação entre representação e realidade, uma vez que as imagens cinematográficas, em sua gênese na modernidade, constituíram uma ligação germinal com noções de "verdade" e "objetividade".

Considerando esse aspecto, a trama das imagens se torna ainda mais significativa no que tange às noções socialmente reiteradas de gêneros. Dentro de toda uma matriz de pensamento dicotômica, os valores consagrados pela modernidade tais como racionalidade, objetividade, trabalho e sociedade foram reiterados e naturalizados como associados à masculinidade, enquanto, ao feminino, associaram-se as emoções, a subjetividade, a natureza, os afetos e tudo mais considerado "intangível". Há que se considerar também que a forma como as sociedades capitalistas organizaram a vida familiar, as separações entre vida privada e social e a divisão de papéis de gênero teve efeitos fundamentais nessa concepção. Durkheim, enquanto homem da sua época, na França do final do século XIX, concebera 
as diferenças problemáticas entre homens e mulheres na vida conjugal perante o advento da modernidade da seguinte forma:

0 homem está ativamente inserido [na vida social], ao passo que a mulher quase só faz assistir-lhe à distância. 0 resultado é ele ser socializado em muito maior grau do que ela. Seus gostos, suas aspirações, seu humor, têm, em grande parte, uma origem coletiva, ao passo que os de sua companheira estão sob influência mais imediata do organismo. Portanto, ele tem necessidades completamente diferentes das dela (DURKHEIM, 2000, p. 504).

Nota-se uma configuração de relações institucionalizada e reforçada através do laço matrimonial que tenderia a relegar as mulheres ao ambiente doméstico, onde lhes eram atribuídas, entre outras funções, a gestão da vida íntima dos afetos e de tudo que deveria ser preservado nos bastidores, à distância da "sociedade" - entendida, grosso modo, como o universo público da vida do trabalho assalariado e das relações econômicas. Estabeleceu-se e, por muito tempo, reproduziu-se uma cisão que colocava do lado da vida privada o feminino, as emoções, o desejo, a subjetividade, o sexo e tudo que remetia a pulsões naturais, que deveriam ser "domesticadas" em nome da civilidade, enquanto, do lado da vida pública, em sociedade, colocavam-se o masculino, a objetividade, a razão pragmática, o trabalho remunerado, a vida econômica, o autocontrole. Tais circunstâncias teriam desdobramentos importantes na utilização pública de imagens de corpos femininos, especialmente na publicidade e posteriormente no cinema. As associações entre feminilidade e elementos ligados às emoções, ao prazer e à subjetividade, que nos discursos fundadores da modernidade deveriam, necessariamente, ser domados pela razão, permitiriam, através do uso de imagens de mulheres a objetivação de estados a princípio abstratos, frequentemente associados a emoções.

Pensando mais especificamente em imagens publicitárias, é notável em muitas dessas peças que, interessa menos apresentar o produto, suas qualidades e funções, mas aludir a determinados estados emocionais, de satisfação ou de estilos de vida apresentados como desejáveis. Nesse sentido, o estudo de Goffman (1979) sobre imagens publicitárias de mulheres em revistas, instiga reflexões interessantes sobre as associações sugeridas entre as imagens das modelos e expressões de descontrole emocional, infantilidade e espontaneidade. $\mathrm{Ou}$ ainda, conforme outros autores:

\begin{abstract}
Em contrapartida, a mídia, de forma ambivalente, legitima a caracterização do feminino em termos de sua fragilidade, sensibilidade, descontrole emocional e consumo, operando em uma lógica homogênea e única de identidade social de gênero (Lopes, 2004), contribuindo para a perpetuação das estereotipias e hegemonia do homem (ROMANI; WINCK; STREY, 2013, p. 266).
\end{abstract}

Havendo se constituído social e historicamente uma percepção que associa diretamente elementos da subjetividade e das emoções à feminilidade, certamente, em muitos casos, o uso publicitário de imagens de mulheres remeteria a esses elementos, objetivando, ao menos em estágios mais iniciais do capitalismo, uma relação de dominação pautada pelo poder econômico de aquisição não tanto de determinado objeto, mas da indescritivel satisfação e do prazer a ele atrelados que ganharia na imagem publicitária os contornos bem definidos de 
um corpo feminino. De maneira perversa, recorrentemente, a mulher se torna, em oposição à "realidade" masculina, a imagem materializada do desejo, da fragilidade, do descontrole, do arrebatamento e de tudo aquilo que, a princípio, seria nocivo ao projeto racionalista e pragmático da modernidade e, portanto, deveria ser controlado ou instrumentalizado. No entanto, a despeito da observação dessas clivagens, a perspectiva que se deseja apontar aqui reconhece esses universos como entrelaçados, embora por vezes se realcem discursivamente suas diferenciações enquanto modos de demarcar fronteiras e relações hierárquicas. Concorda-se aqui com Eva Illouz que:

[...] repertórios culturais baseados no mercado moldam e impregnam as relações interpessoais e afetivas, e as relações interpessoais encontram-se no epicentro das relações econômicas. Mais exatamente, os repertórios do mercado se entrelaçam com a linguagem da psicologia e, combinados, os dois oferecem novas técnicas e sentidos para cunhar novas formas de sociabilidade (ILLOUZ, 2007, p. 13).

Embora não de forma generalizada, mas significativa, muitas das imagens que se difundem nos meios de comunicação - ainda que direcionadas a diferentes públicos - se constituem historicamente a partir de olhares masculinos. Assim, as relações que se estabelecem entre imagens socialmente reconhecidas, fixadas na memória pela repetitividade, incorporadas nas práticas cotidianas e, muitas vezes, naturalizadas, tendem a reiterar olhares masculinos, uma vez que acedem a um repertório vasto e reconhecido de imagens produzidas sob esses olhares. Nesse sentido, em muitos de seus usos, imagens de corpos femininos no ci- nema e na publicidade materializam tudo o que habitaria o universo intangível de fantasias, desejos e emoções masculinas. Conforme Higonnet:

O século XX acrescentou o cinema à cultura visual. Imensamente popular, o cinema desempenhou um importantíssimo papel na definição dos sexos da cultura de massa. 0 cinema clássico representa as mulheres como prazer visual, objetos de um olhar masculino. Atrizes como Marilyn Monroe tornaram-se ícones da sexualidade, imagens estáticas cujo fascínio reside nas fantasias que sobre elas são projetadas (HIGONNET, 1991, p. 415).

Disso decorre a problemática que torna tão atual quanto relevante investigar crítica e minuciosamente a construção social de imagens e imaginários do "feminino", operada em grande medida, através de mídias audiovisuais: trata-se, ao mesmo tempo, como efeito de relações de poder historicamente constituídas, de reduzir o feminino às suas imagens conforme olhares masculinos, como meio de objetivação de elementos frequentemente considerados como desprovidos de materialidade, como é o caso das emoções e de sua expressividade, tratadas historicamente como competências distintamente femininas (CANCIAN, 1986). Do que se deriva que, suas construções em forma de imagens ao longo do século XX, executadas majoritariamente por homens (diretores de cinema, fotógrafos de revistas) tornariam visíveis, conforme seus olhares, aspectos selecionados, realçados e ressignificados de objetos considerados abstratos. Contudo, com a forte impressão de realidade instigada pela fotografia e pelo cinema, aspectos interpretativos das imagens, que só se tornam reconhecíveis a 
partir de relações, são facilmente tomados irrefletidamente, como retratos autênticos da "realidade".

\section{Considerações finais}

A partir das reflexões aqui suscitadas, deduz-se que, frequentemente, o uso de imagens de personagens femininas em filmes e anúncios publicitários não se propõe necessariamente a representar sua realidade, mas em estabelecer precisamente ligações com imaginários não somente sobre feminilidades, mas de forma difusa, sobre afetividade, emoções, prazeres, desejos, paixões e outros elementos às vezes entendidos como ininteligíveis. Nisso, é contundente que esse imaginário do feminino em questão seja marcadamente heterossexualizado. Mesmo filmes e campanhas publicitárias que seriam direcionadas a um suposto público feminino são moderados por olhares masculinos por se constituírem a partir de relações com outras imagens produzidas conforme esses olhares.

Reconhece-se, portanto, a relevância social e política de se problematizar a constituição de imagens de gêneros que se inserem reiteradamente na produção e manutenção de relações desiguais. Contudo, acredita-se que ainda há questões metodológicas significativas a serem debatidas de forma pormenorizada e cuidadosa, sendo que recorrentes clivagens que estabelecem as imagens - na condição de representações - em oposição à realidade, eventualmente perdem de vista as complexas relações de mútua construção que se estabeleceriam entre esses dois elementos pretendidos por muitos como auto -excludentes. Este artigo, sem dúvida, é insuficiente para resolver todas essas questões, sendo seu propósito, principalmente, suscitá -las, instigá-las e promover outras possibi- lidades para pensar a questão das imagens relacionadas a gêneros. Considera-se que a análise de imagens pautada pela noção frequentemente vaga de representação não contempla satisfatoriamente as relações sociais que se estabelecem, primeiramente entre imagens e os significados a elas atribuídos, a partir das quais se constroem sentidos que orientam ações concretas e formas não somente de olhar e interpretar as imagens do mundo, mas o mundo em si. Formas constituídas não pelo realismo das imagens, mas por relações de sentido que se construíram histórica e processualmente entre imagens e discursos e, com isso, instituíram formas de perceber o mundo e de se apresentar e se constituir, ao mesmo tempo, dentro dele e perante ele, perfomativamente.

\section{Referências}

ALMEIDA, H. B. "Muitas mais coisas": telenovela, consumo e gênero. 2001. 328 f. Tese (Doutorado em Antropologia) - Faculdade de Filosofia, Letras e Ciências Humanas, Universidade de São Paulo, São Paulo, 2001.

AUMONT, J. ; MARIE, M. Dicionário teórico e crítico de cinema. São Paulo: Papirus, 2009.

BERGER, P.; LUCKMANN, T. A construção social da realidade. Petrópolis: Vozes, 1983.

BESSA, K. Os festivais GLBT de cinema e as mudanças estético-políticas na constituição da subjetividade. Cadernos Pagu, n. 28, p. 257- 283, jan./ jun. 2007.

BUTLER, J. Problemas de gênero: feminismo e subversão da identidade. Rio de Janeiro: Civilização Brasileira, 2013.

Corpos que pesam: sobre os limites discursivos do sexo. In. LOURO, G. L. (Org.). 0 corpo educado: pedagogias da sexualidade. Belo Horizonte: Autêntica, 2000, p.151-175. 
CANCIAN, F. The feminization of love. Signs, n. 4, v. 11, p. 692-709, 1986.

COLLING, L. et al. Um panorama dos estudos sobre mídia, sexualidades e gêneros não normativos no Brasil. Revista Gênero, Niterói, v. 12, n. 2, p. 77108, $1^{\circ}$. sem. 2012.

DURKHEIM, E. O suicídio: estudo de sociologia. São Paulo: Martins Fontes, 2000.

GOFFMAN, E. Gender Advertisement. New York: Harper \&t Row, 1979.

GOMBRICH, E. H. Arte e ilusão. São Paulo: Martins Fontes, 2007.

HALL, S. Representation: cultural representations and signifying practices. London: SAGE Publications, 1997.

HIGONNET, A. Mulheres, imagens e representações. In: PERROT, M.; DUBY, G. História das mulheres no Ocidente v. 4. Porto-PT: Afrontamento, 1991, p.325-349.

ILLOUZ, E. 0 amor nos tempos do capitalismo. Rio de Janeiro: Zahar, 2007.

LAURETIS, T. Tecnologia do Gênero In: HOLLANDA, H. B. (Org.). Tendências e impasses: o feminismo como crítica da cultura. Rio de Janeiro: Rocco, 1994.

LOURO, G. L. Cinema e sexualidade. Educação $\&$ Realidade, 33(1), p. 81-98, jan./jun. 2008.

MARTIN, M. A linguagem cinematográfica. São Paulo: Brasiliense, 2003.

MENEZES, P. Representificação: as relações (im) possiveis entre cinema documental e conhecimento. RBCS, v.18, n. 51, p. 87-97, fev. 2003.

- À meia luz: cinema e sexualidade nos anos 70. São Paulo: Editora 34, 2001.

MORIN, E. Cultura de massas no século XX: o espírito do tempo - 1: Neurose. São Paulo Forense, 2002.

PASSERINI, L. Mulheres, consumo e cultura de massas. In: PERROT, M.; DUBY, G. História das mulheres no Ocidente v. 4. Porto-PT: Afrontamento, 1991.
RABENHORST, E. R.; CAMARGO, R. P. (Re)presentar: contribuições das teorias feministas à noção de representação. Estudos feministas, Florianópolis 21(3), p.981-1000, set./dez. 2013.

ROMANI, P.; WINCK, G.; STREY, M. Consumismo na pós-modernidade: uma questão de gênero? Ciências Sociais Unisinos, v. 49, n. 3, p. 263-268, set/dez 2013.

ROSSI, T. Uma sociologia do amor romântico: Hollywood, 1990-2000. São Paulo: Alameda, 2015.

SORLIN, P. Sociologie du cinéma. Paris: Aubier Montaigne, 1982.

WEBER, M. Economia e Sociedade, v. I. Brasília: UNB, 2000.

Sobre a "objetividade" do conhecimento nas ciências sociais. Ensaios sobre a teoria das ciências sociais. São Paulo: Centauro, p. 1-74, 2008.

WRIGHT MILLS, C. 0 homem no centro: o designer. Sobre o artesanato intelectual e outros ensaios. Rio de Janeiro: Zahar, p. 65-80, 2009. 
RESUMO

Este é um artigo de caráter teórico-metodológico, no que se discutem os usos do termo "representação" na literatura de estudos de gêneros, problematizando de forma mais específica o uso do termo em trabalhos que tratam de imagens convencionadas e reconhecidas como "femininas" especialmente no cinema e na publicidade. Argumenta-se que o termo representação nesses estudos de imagens seria analiticamente problemático, especialmente quando emaranhado em significações políticas e sociais. Sem desconsiderar a importância de se estudar criticamente os usos e a construção de imagens de gêneros, propõe-se abordagens alternativas que não reproduzam o antagonismo entre imagem - tipicamente tratada como representação - e "realidade", sugerindo, ao contrário, explorar relações sociais entre imagens e seus desdobramentos na construção social de diferenças de gêneros.

\section{PALAVRAS-CHAVE}

Gêneros. Representações. Imagens. Sociologia do Cinema.

\section{ABSTRACT}

This is a theoretical and methodological paper, discussing the uses of the term "representation" in the literature of gender studies, questioning more specifically the use of the term dealing with images conventionally recognized as "feminine ', especially in films and advertising. It is argued that the term "representation" in such studies would be analytically problematic, especially when imbricated of its political and social meanings. Without ignoring the importance of critically studying the uses and the construction of genres by images, we propose other approaches that do not reproduce the antagonism between image - typically treated as representation - and "reality", suggesting instead, exploring the social relationships between images and its consequences on the social construction of gender differences.

\section{KEYWORDS}

Genders. Representations. Images. Cinema Sociology. 
